\title{
O PRESTADOR DE SAÚDE E O CONTROLE SOCIAL: Protagonista que faz a diferença.
}

\author{
Gianni Lara \\ Assessora Técnica da AHMG, Conselheira Estadual de Saúde e \\ Conselheira Municipal de Saúde de BH. \\ nucleotecnico@ahmg.com.br
}

Constitucionalmente, as ações e os serviços de saúde são de relevância pública, ou seja, a saúde é um bem prioritário e uma condição para que o cidadão possa ter uma vida digna e produtiva. Desta forma, compete ao Estado garantir as condições necessárias ao atendimento das demandas da população, ficando na responsabilidade do prestador a obrigação de oferecer uma atenção adequada e com qualidade.

Todavia, o setor é complexo e os desafios são enormes. A busca de parcerias passa a ser de vital importância para o devido cumprimento dos objetivos legais da saúde. Assim, a participação pró-ativa do prestador junto aos Conselhos de Saúde propicia o aprimoramento da interação e articulação entre os entes que o constitui (usuários, trabalhadores, gestores e prestadores) impactando positivamente na efetividade e eficácia do controle social, podendo refletir assim na melhoria da qualidade dos serviços prestados a população.

Para Pedrosa (1997), em termos coletivos, pode-se dizer que o conselho de saúde, também denominado Controle Social, é um espaço ainda desconhecido e o seu reconhecimento como sendo a realidade é um processo que também depende de dois fatores: de como o sujeito concebe o mundo no qual atua e como se posiciona diante desse mundo cheio de conflitos e possibilidades. E este desconhecimento perdura nos dias atuais visto que, por exemplo, o número de artigos publicados sobre o assunto é ínfimo.

Participar é conquista, é processo e não concessão. Não pode ser vista como dádiva dos administradores ou governantes temporários, mas sim encarada dentro da noção do princípio ético da responsabilidade como um dever do cidadão de participar do processo de tomada de decisões sobre as políticas públicas, segundo Fortes (2009).

Os Conselhos de Saúde são instâncias internas à estrutura do SUS, órgãos colegiados e de caráter permanente sendo que suas deliberações são, em geral, resultados de negociações com os órgãos executores para garantir o processo democrático e a qualidade das ações.
A Lei $n^{\circ}$. 8.142/1990 explicita a composição dos Conselhos de Saúde e garante a representação dos prestadores de serviços na elaboração, implementação e fiscalização das políticas prioritárias da saúde pública. Compete também ao prestador atuar de forma colaborativa nos processos apurativos de irregularidades de convênios e contratos de serviços que the couber, quando por ventura for denunciado por parte dos usuários.

No guia de referência para conselheiros municipais (MINISTÉRIO DA SAÚDE,2001) são apontadas cinco condições que contribuem para um melhor desempenho dos Conselhos:

1. AUTONOMIA - do ponto de vista administrativo, financeiro e técnico. Devem ser garantidos no orçamento das Secretarias Municipais e Estaduais de Saúde recursos para o desenvolvimento do trabalho, desde a garantia do espaço físico até pessoal de apoio e administrativo para a execução das atividades.

2. ORGANICIDADE - é caracterizado pela infra-estrutura básica para realização dos encontros entre os conselheiros. Os Conselhos devem ter instrumento administrativo próprio, como o Regimento Interno, que regulamente o seu funcionamento para orientar os processos de discussão, regularidade das reuniões, votação e outros encaminhamentos próprios das atividades dos conselheiros.

3. PERMEABILIDADE - o estabelecimento de canais de recepção das demandas sociais, das necessidades de saúde emergentes que deverão ser estabelecidas nas pautas de discussões dos Conselhos para serem negociadas a operacionalidade por parte dos órgãos executores - a Secretaria de Saúde e os Prestadores.

4. VISIBILIDADE - é um dos pontos centrais. Seria colocar o usuário no centro do processo, numa relação de co-responsabilidade (governo - trabalhadores de saúde - prestadores de serviços e usuários). Daí a importância dos meios de comunicação e da criação de 
instrumentos que possibilitem a democratização da informação, garantindo maior visibilidade e transparência.

5. ARTICULAÇÃO - a articulação deve envolver todas as representações: Conselho Local (das unidades de saúde), Conselhos Municipal, Estadual e Nacional, Comissões Intergestores Bipartide e Tripartide, Conselhos de Secretários Municipais e Estaduais de Saúde, bem como as instituições da área da saúde. Além disso, é importante a articulação com outros setores da sociedade.

Em 1996, o relatório final da $10^{a}$ Conferência Nacional de Saúde já havia definido, com clareza, o caráter deliberativo e o poder fiscalizador dos Conselhos de Saúde, com ênfase na democratização da informação, a saber:

$\checkmark$ O livre acesso a todas as informações sobre produção de serviços;

$\checkmark$ Horário de trabalho - especialmente plantões;

$\checkmark$ Custos de atendimento;

$\checkmark$ Indicadores de saúde;

$\checkmark$ Elaboração e implementação de Planos de Saúde;

$\checkmark$ Metas, propostas, programas e projetos;

$\checkmark$ Informações relativas ao saneamento básico e ao meio ambiente;

$\checkmark$ Contrato e convênios com a rede privada e filantrópica;

$\checkmark$ Implantação de consórcios intermunicipais;

$\checkmark$ Orçamento para a saúde;

$\checkmark$ Extratos bancários e fluxo de caixa diário das contas do Fundo de Saúde;

$\checkmark$ Auditorias e fiscalizações.

$\checkmark$ Qualquer outra informação solicitada pelos conselheiros de saúde. Sendo que a sonegação de informações deve implicar crime de responsabilidade.

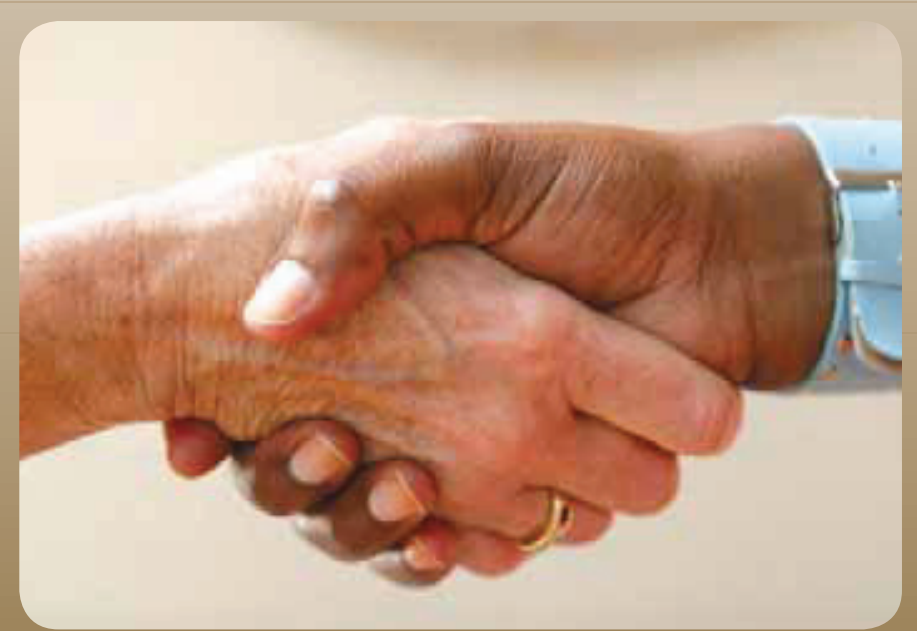

Ressalta-se ainda que, não cabe neste espaço a manifestação do interesse individual e sim o comprometimento do conselheiro no julgamento da pertinência, da viabilidade e das prioridades das ações de saúde pública. Este sujeito coletivo tão bem caracterizado por Gastão Campos (1997) deve ser capaz de conquistar a confiança e vislumbrar as expectativas dos cidadãos-usuários.

Corrobora Tavares (2010) ao afirmar também que a transparência na gestão pública é uma questão que por mais discutida, ainda merece muitos estudos e questionamentos, uma vez que ainda não alcançou o nível de solução satisfatório. A transparência é uma ferramenta que inibe a corrupção, assim se o indivíduo tiver que prestar contas de suas ações, presume-se que a probabilidade de ele agir de forma responsável e planejada será maior.

Por todas estas questões apontadas, é importante considerar a efetiva atuação, nos conselhos, dos prestadores de serviço como um dos importantes protagonistas na gestão do sistema. Pois, somente a articulação entre os atores que têm olhares distintos, nem sempre convergentes e harmônicos, pode ajudar no processo de discussão, inclusive nos aspectos econômicos e financeiros, que busque um consenso em defesa dos princípios e diretrizes para um sistema público verdadeiramente equânime e resolutivo.

Assis (2003) reforça ainda que a informação com qualidade é um recurso essencial para o desempenho eficaz do controle social. Portanto, o prestador conselheiro também é chamado a assumir, com competência e responsabilidade, o papel de fornecedor de dados técnicos e científicos na busca de soluções para os desafios do setor saúde, bem como apresentando sugestões e críticas construtivas para consolidação do sistema.

Assim, diante da atualidade de discussão do papel do controle social no SUS, Silva e Coelho (2010) merecem apoio quando afirmam que a simples implementação da participação social não garante mudanças de paradigma, mas, propicia o debate da agenda da gestão, o compartilhamento do poder e da responsabilidade sobre as ações e serviços de saúde. 


\section{REFERÊNCIAS BIBLIOGRÁFICAS:}

ASSIS, Marluce Maria Araújo; VILLA, Tereza Cristina Scatena. O controle social e a democratização da informação: um processo em construção. Rev. Latino-Am. Enfermagem, Ribeirão Preto, v. 11, n. 3, June 2003. Available from <http://www.scielo.br/scielo.php?script=sci_arttext\&pid=S0104$11692003000300017 \& \mathrm{lng}=\mathrm{en \&} \mathrm{nrm}=\mathrm{iso}>$. access on 16 Aug. 2010 . doi: 10.1590/S010411692003000300017.

BRASIL. Ministério da Saúde. Dispõe sobre a participação da comunidade na gestão do Sistema Único de Saúde (SUS\} e sobre as transferências intergovernamentais de recursos financeiros na área da saúde e dá outras providências. Lei $n^{\circ}$ 8.142, de 28 de dezembro de 1990. Disponível em: http:// www.planalto.gov.br/ccivil_03/Leis/L8142.htm. Acesso em: 22 de setembro 2010.

FORTES, P. A Ética do Controle Social na Saúde e os Conselhos de Saúde. Revista Bioética, América do Norte, 54112009.

CAMPOS, Gastão W.S. Considerações sobre a Arte e a Ciência da Mudança: Revolução das Coisas e Reforma das Pessoas. O Caso da Saúde. Inventando a Mudança na Saúde. Saúde em Debate. $2^{a}$ Edição. Capítulo 1. p 29-87. 1997.

MINISTÉRIO DA SAÚDE (BR). Coordenação de Projetos de Promoção de Saúde. O SUS e o controle social: guia de referência para conselheiros municipais. Brasília; 2001. Disponível: http://www.fo.usp. $\mathrm{br} /$ departamentos/social/saude_coletiva/MOSUS.pdf. Acesso em: 25 de agosto 2010.

MINISTÉRIO DA SAÚDE (BR). Relatório final da $10^{a}$ Conferência Nacional de Saúde. Brasília; 1996. Disponível: http://bvsms.saude.gov.br/bvs/publicacoes/10conferencia.pdf. Acesso em: 25 de agosto 2010.

PEDROSA, José Ivo dos Santos. A construção do significado de controle social com conselheiros de saúde no Estado do Piauí, Brasil. Cad. Saúde Pública, Rio de Janeiro, v. 13, n. 4, Oct. 1997. Available from <http://www.scielo.br/scielo.php?script=sci_arttext\&pid=S0102-311X1997000400 $016 \&$ lng $=$ en\&nrm=iso $>$. access on 16 Aug. 2010. doi: 10.1590/S0102-311X1997000400016.

SILVA, Regina Helena L.P.; COELHO, Maria Cristina R.V. O Desafio da gestão com controle social. Desafios e Inovações na Gestão do SUS em Belo Horizonte: a experiência de 2003 a 2008. $1^{\text {a }}$ Edição. Capítulo 13. p 355-359. 2010.

TAVARES, Rosângela M. S. Transparência nos Municípios: As informações disponibilizadas atendem a demanda do Controle Social na Saúde? Monografia. Bacharel em Ciências Contábeis. Universidade Federal de Minas Gerais - UFMG, Belo Horizonte - MG, 2010. 


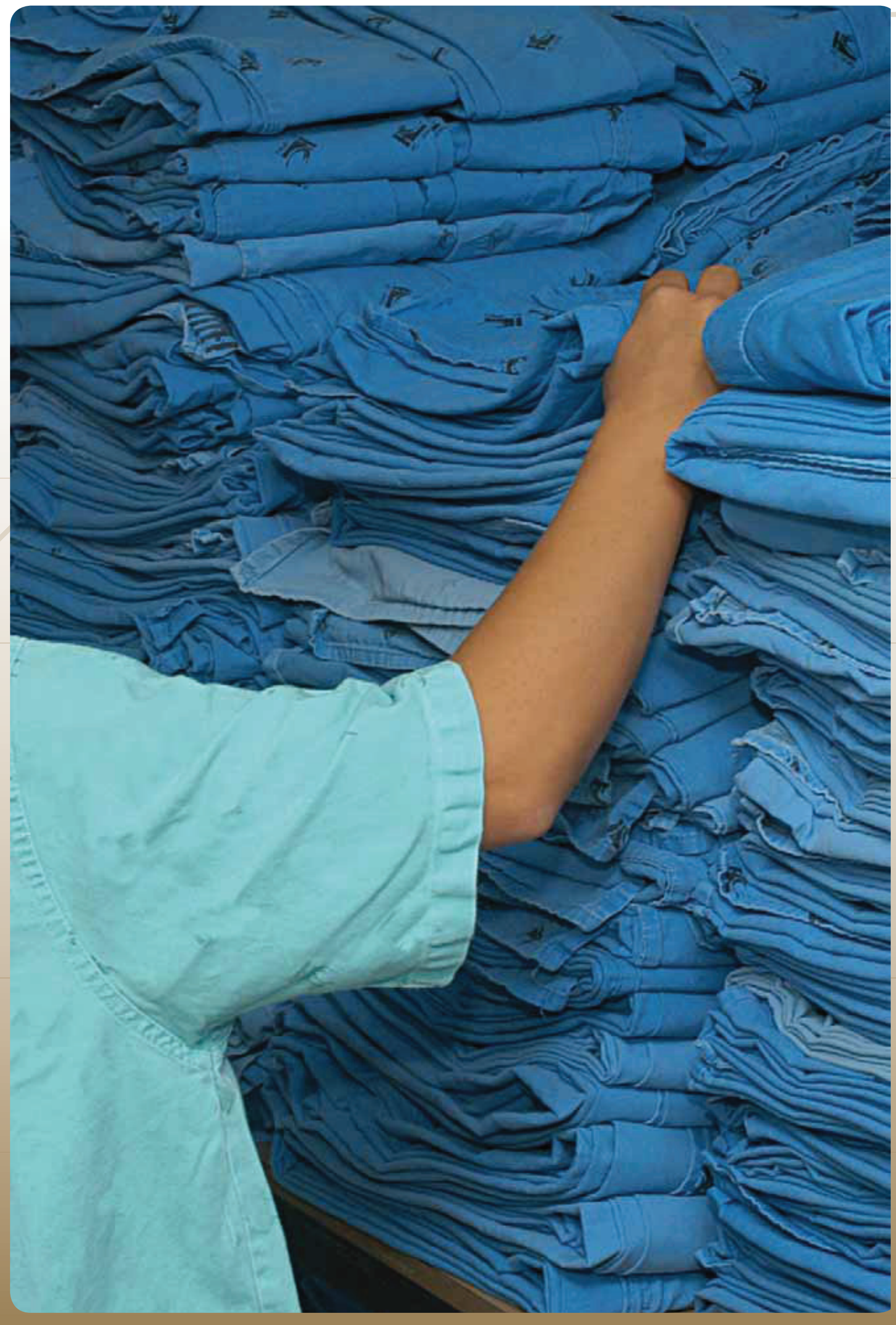

